\title{
Use of personal child health records in the UK: findings from the millennium cohort study
}

\author{
Suzanne Walton, Helen Bedford, Carol Dezateux, the Millennium Cohort Study Child Health Group
}

\begin{abstract}
Objectives The personal child health record (PCHR) is a record of a child's growth, development, and uptake of preventive health services, designed to enhance communication between parents and health professionals. We examined its use throughout the United Kingdom with respect to recording children's weight and measures of social disadvantage and infant health.

Design Cross sectional survey within a cohort study. Setting UK.

Participants Mothers of 18503 children born between 2000 and 2002, living in the UK at 9 months of age.
\end{abstract}

Main outcome measures Proportion of mothers able to produce their child's PCHR; proportion of PCHRs consulted containing record of child's last weight; effective use of the PCHR (defined as production, consultation, and child's last weight recorded).

Results In all, 16917 (93\%) mothers produced their child's PCHR and 15138 (85\%) mothers showed effective use of their child's PCHR. Last weight was recorded in 97\% of PCHRs consulted. Effective use was less in children previously admitted to hospital, and, in association with factors reflecting social disadvantage, including residence in disadvantaged communities, young maternal age, large family size (four or more children; incidence rate ratio $0.87 ; 95 \%$ confidence interval 0.83 to 0.91 ), and lone parent status $(0.88 ; 0.86$ to 0.91$)$.

Conclusions Use of the PCHR is lower by women living in disadvantaged circumstances, but overall the record is retained and used by a high proportion of all mothers throughout the UK in their child's first year of life. PCHR use is endorsed in the National Service Framework for Children and has potential benefits which extend beyond the direct care of individual children.

\section{Introduction}

The personal child health record (PCHR) is a booklet given to new parents in the United Kingdom, to be used as the main record of their child's growth, development, and uptake of preventive health services. The ethos behind the record is improved communication, enhanced continuity of care, and increased parental understanding of their child's health and development. ${ }^{1}$ We examined use of the PCHR throughout the UK for recording children's weight and explored its associations with measures of social disadvantage and infant health, using cross sectional data from the millennium cohort study. ${ }^{2}$

\section{Methods}

In the millennium cohort study, parents of 18819 children born between 2000 and 2002 (response rate
$72 \%$ ) were interviewed on a range of topics when their children were 9 months old. ${ }^{3}$ Interviewers asked parents to produce their child's PCHR and encouraged them to consult it to confirm their child's last weight. We analysed responses from 18503 natural mothers of singleton and first born infants (of multiple births) with three measures: the proportion of mothers who produced the record; the proportion of records that documented the child's last weight; and the proportion of mothers showing effective use of the record, defined as producing and consulting the record and the weight having been documented. We explored these outcomes in association with a range of geographical, maternal, family, and infant characteristics. We used STATA 8.2 (StataCorp, College Station, Texas) to do $\chi^{2}$ tests and Poisson regression using sample weights and the software's SVY series of commands to allow for survey design. ${ }^{3}$

Geographical, maternal, and infant characteristics associated with effective use of the personal child health record. Values are absolute numbers (weighted percentages) and rate ratios ( $95 \%$ confidence intervals)

\begin{tabular}{|c|c|c|c|}
\hline \multirow[b]{2}{*}{ Measures } & \multirow[b]{2}{*}{ No (weighted \%)* } & \multicolumn{2}{|c|}{ Rate ratio $(95 \% \mathrm{Cl})$} \\
\hline & & Unadjusted & Adjusted† \\
\hline \multicolumn{4}{|l|}{ Country: } \\
\hline England & $11500(87)$ & 1 & 1 \\
\hline Wales & $2755(81)$ & 0.94 (0.91 to 0.97$)$ & 0.96 (0.93 to 0.99) \\
\hline Scotland & $2327(71)$ & 0.82 (0.77 to 0.88$)$ & $0.80(0.75$ to 0.86$)$ \\
\hline Northern Ireland & $1916(79)$ & 0.91 (0.88 to 0.94$)$ & 0.92 (0.89 to 0.96$)$ \\
\hline \multicolumn{4}{|l|}{ Ward type: } \\
\hline Advantaged & $7303(88)$ & 1 & 1 \\
\hline Disadvantaged & $8813(79)$ & 0.90 (0.87 to 0.93 ) & 0.95 (0.93 to 0.98$)$ \\
\hline Ethnic minority & $2382(84)$ & 0.95 (0.91 to 1.00$)$ & 0.99 (0.95 to 1.03$)$ \\
\hline $\begin{array}{l}\text { Maternal age at cohort } \\
\text { baby's birth }\end{array}$ & & 1.04 (1.04 to 1.05$)$ & 1.03 (1.01 to 1.04$)$ \\
\hline $\begin{array}{l}\text { Maternal age at first ever } \\
\text { live birth } \ddagger\end{array}$ & & 1.06 (1.05 to 1.07$)$ & 1.01 (1.00 to 1.02$)$ \\
\hline \multicolumn{4}{|c|}{ Total number of children in household: } \\
\hline 1 & 7666 (86) & 1 & 1 \\
\hline 2 or 3 & $9283(85)$ & 0.99 (0.97 to 1.00$)$ & 0.96 (0.95 to 0.98$)$ \\
\hline 4 or more & $1549(74)$ & 0.86 (0.82 to 0.90$)$ & 0.87 (0.83 to 0.91$)$ \\
\hline \multicolumn{4}{|c|}{ Maternal academic qualifications: } \\
\hline Some & $14854(87)$ & 1 & 1 \\
\hline None & $3596(75)$ & 0.87 (0.84 to 0.89$)$ & 0.96 (0.94 to 0.98$)$ \\
\hline \multicolumn{4}{|l|}{ Lone parent: } \\
\hline No & $15327(87)$ & 1 & 1 \\
\hline Yes & $3171(71)$ & 0.81 (0.79 to 0.84$)$ & 0.88 (0.86 to 0.91$)$ \\
\hline \multicolumn{4}{|c|}{ Maternal longstanding illness: } \\
\hline No & $14598(85)$ & 1 & 1 \\
\hline Yes & 3892 (83) & 0.98 (0.96 to 1.00$)$ & 0.98 (0.96 to 0.99$)$ \\
\hline \multicolumn{4}{|l|}{ Cohort pregnancy: } \\
\hline Planned & 9978 (89) & 1 & 1 \\
\hline Unplanned & $8489(79)$ & 0.89 (0.87 to 0.90$)$ & 0.96 (0.94 to 0.97$)$ \\
\hline \multicolumn{4}{|l|}{ Baby's hospital admissions: } \\
\hline None & $15808(86)$ & 1 & 1 \\
\hline One or two & 2507 (81) & 0.94 (0.92 to 0.97) & 0.94 (0.92 to 0.97$)$ \\
\hline Three or more & $181(72)$ & 0.84 (0.75 to 0.93$)$ & 0.89 (0.81 to 0.97$)$ \\
\hline Total & $18498(85)$ & & \\
\hline $\begin{array}{l}{ }^{*} \text { Missing values are mater } \\
\text { maternal academic qualific } \\
\text { admissions: } 2 \text {. } \\
\dagger \text { The adjusted rate ratios t } \\
\text { †Per five year increase. }\end{array}$ & $\begin{array}{l}\text { al age at cohort baby } \\
\text { tions: } 48 \text {; maternal lo } \\
\text { ke into account all ot }\end{array}$ & $\begin{array}{l}\text { th: 7; maternal age at } \\
\text { anding illness: } 8 \text {; plann } \\
\text { actors included in the }\end{array}$ & $\begin{array}{l}\text { live birth: } 641 \text {; } \\
\text { ancy: } 31 \text {; hospital }\end{array}$ \\
\hline
\end{tabular}




\section{What is already known on this topic}

Use of the personal child health record to document a child's health, growth, and development has various benefits

\section{What this study adds}

Use of the record is lower in women living in disadvantaged circumstances, but overall it is retained and used by a high proportion of mothers throughout the United Kingdom in their child's first year of life

\section{Results}

Overall, 16917 mothers (93\%) produced the PCHR and 15883 (weighted percentage 88\%) consulted it to check their child's last weight. Of the PCHRs consulted, $97 \%$ had the weight documented. Thus, 15138 mothers $(85 \%)$ showed effective use of the record. All outcome rates were highest in England and lowest in Scotland.

The ability to produce the record was significantly lower in disadvantaged electoral wards $(89 \%)$ compared with advantaged wards $(95 \%)$ and ethnic minority wards $(94 \%))^{3}$ Younger mothers and those with fewer academic qualifications and lower socioeconomic status were less likely to produce the PCHR, as were mothers with larger families $(86 \%$ if four or more children); women with longstanding illness $(91 \%)$ or a history of depression (91\%); and lone parents (83\%). A similar range of factors were associated with the proportion of PCHRs that contained documentation of the child's last weight.

Multivariable regression analyses showed that less effective use of the PCHR was associated with factors reflecting social disadvantage, including residence in disadvantaged communities, young maternal age, larger family size, low maternal educational attainment, and being a lone parent (table). Effective use was also less in mothers who reported that their child had been admitted to hospital.

\section{Discussion}

Although use of the personal child health record is lower by women living in disadvantaged circumstances, overall, the record is retained and used by a high proportion of all mothers throughout the UK in their child's first year of life. The apparent association of hospital admissions with less PCHR use is of concern and may reflect a number of factors.

PCHR use is endorsed in the National Service Framework for Children. ${ }^{4}$ The new national standard PCHR has been designed to reflect current policies. ${ }^{5}$ Using the PCHR to its full potential has implications that extend beyond the direct care of the individual child. The findings from this study are therefore of relevance to healthcare staff, to public health (in respect to potential uses of these data), and to the NHS's information strategy (in terms of consideration of the PCHR within broader health information policies).

We thank all the millennium cohort families for their participation and Professor Heather Joshi, director of the millennium cohort study and her colleagues in the millennium cohort study management team at the Centre for Longitudinal Studies, Institute of Education, University of London. The other members of the Millennium Cohort Study Child Health Group who contributed to this work were Suzanne Bartington, Neville Butler, Tim Cole, Lucy Griffiths, Catherine Law, Catherine Peckham, Lamiya Samad, and Rosemary Tate.

Contributors: SW, HB, and $\mathrm{CD}$ developed the research questions and data analysis and interpretation. They wrote the first draft of the paper. Members of the Millennium Cohort Study Child Health Group contributed to the paper through analysis and construction of explanatory variables and commented on data interpretation and early drafts of the manuscript. SW is guarantor.

Funding: The millennium cohort study is funded by grants from the Economic and Social Research Council and a consortium of government departments led by the Office for National Statistics. SW completed this work while on academic secondment from the London Deanery Public Health Training Scheme. Research at the Institute of Child Health and Great Ormond Street Hospital for Children NHS Trust benefits from R\&D funding received from the NHS Executive.

Competing interests: $\mathrm{HB}$ is chairwoman of the PCHR subcommittee of the Royal College of Paediatrics and Child Health. This paper was written in a personal capacity.

Ethical approval: The millennium cohort study was approved by the London Multicentre Research Ethics Committee. This analysis needed no further approval.

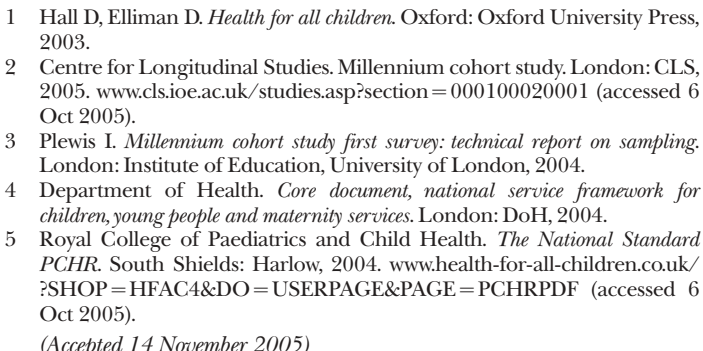

\section{One hundred years ago}

\section{Modern prescriptions}

ComplainTs are often heard that the new-fledged doctors of the present day cannot write prescriptions. Indeed it has been said by those who claim to speak with authority that even among older men prescriptions of the classic type have been superseded by the use of ready-made preparations. Dr. M. Clayton Thrush, a Philadelphia physician, has been at some pains to investigate the subject. As the result of observations made on 500 prescriptions in each of two of the leading pharmacies of Philadelphia, he has arrived at the following conclusions: (1) That the trend of modern prescription writing is in favour of proprietary preparations. (2) That the use of polypharmaceutic preparations is diminishing to a great extent, and their use is chiefly confined to the older practitioners. (3) That the number of incompatibilities observed is greater than it should be. (4) That the metric system is but little employed at the present time in prescription writing, a state of things which Dr. Thrush thinks is to be deplored. (5) That over one-third of the prescriptions are incorrectly written; this is especially true among the younger practitioners. (6) That certain non-official preparations are very popular, and that some of these deserve admission to the United States Pharmacopoeia. (7) That the more educated the physician the greater the use of the pharmacopoeial preparations, and the greater the tendency to simple instead of complex, non-scientific, polypharmaceutic and proprietary preparations. (BMJ 1905;i:614) 